\title{
Arzanol, a Potent mPGES-1 Inhibitor: Novel Anti-Inflammatory Agent
}

\author{
Pankaj S. Kothavade, Dnyaneshwar M. Nagmoti, Vipin D. Bulani, and Archana R. Juvekar \\ Department of Pharmaceutical Sciences and Technology, Institute of Chemical Technology, Nathalal Parekh Marg, \\ Matunga, Mumbai 400 019, India \\ Correspondence should be addressed to Archana R. Juvekar; arj04@rediffmail.com
}

Received 8 August 2013; Accepted 2 September 2013

Academic Editors: A. A. Romanovsky and A. Tanoue

Copyright (C) 2013 Pankaj S. Kothavade et al. This is an open access article distributed under the Creative Commons Attribution License, which permits unrestricted use, distribution, and reproduction in any medium, provided the original work is properly cited.

\begin{abstract}
Arzanol is a novel phloroglucinol $\alpha$-pyrone, isolated from a Mediterranean plant Helichrysum italicum (Roth) Don ssp. microphyllum which belongs to the family Asteraceae. Arzanol has been reported to possess a variety of pharmacological activities. However, anti-inflammatory, anti-HIV, and antioxidant activities have been studied in some detail. Arzanol has been reported to inhibit inflammatory transcription factor NF $\kappa$ B activation, HIV replication in T cells, releases of IL-1 $\beta$, IL-6, IL- 8 , and TNF- $\alpha$, and biosynthesis of $\mathrm{PGE}_{2}$ by potentially inhibiting mPGES-1 enzyme. Diversity of mechanisms of actions of arzanol may be useful in treatment of disease involving these inflammatory mediators such as autoimmune diseases and cancer. This review presents comprehensive information on the chemistry, structure-activity relationship, and pharmacological activities of arzanol. In addition this review discusses recent developments and the scope for future research in these aspects.
\end{abstract}

\section{Introduction}

Inflammation is the reaction of living tissue to injury, in which a series of changes of the terminal vascular bed, blood, and connective tissue tends to eliminate the injurious agent and to repair the damaged tissue [1]. Inflammatory process involves evidence of prostaglandins, leukotrienes, histamine, bradykinin, platelet-activating factor (PAF), and interleukins (IL) [2]. Eicosanoids, namely, prostaglandins and leukotrienes, are key substances involved in inflammatory reactions; hence, these eicosanoids inhibition is major target for anti-inflammatory agents. Nonselective cyclooxygenase (COX) inhibitors (Diclofenac, Indomethacin), selective COX-2 inhibitors (Celecoxib, Etoricoxib), phospholipase $\mathrm{A}_{2}\left(\mathrm{PLA}_{2}\right)$ inhibitors (Corticosteroids) and newer therapies such as antitumour necrosis factor (TNF)- $\alpha$ therapy (Etanercept, Infliximab, and Adalimumab), and anti-CD20 therapy (Rituximab) are often used to inhibit the underlying immune process. However, long-term clinical use of these agents is associated with risk of adverse effects, as they have been linked with gastrointestinal toxicity and an increased risk of adverse cardiovascular events. In recent years, researchers are involved in finding new categories of the development of other enzymatic targets within the arachidonic acid pathway, including the $\mathrm{PGE}_{2}$ synthase (PGES) to overcome the side effect of existing compounds. Several compounds like MF63, NS-398, MK-866, and Triclosan are microsomal PGE $_{2}$ synthase (mPGES) inhibitors, which were assayed for in vitro studies, but some of them have shown poor bioavailability and hepatotoxicity [3].

Helichrysum italicum (Roth) Don ssp. microphyllum is mediterranean plant belongs to the Asteraceae family. This plant is widespread in the areas of stony, arid, sandy mediterranean region along the east coast and on the islands of the Adriatic Sea [4]. H. italicum has been reported to possess antiinflammatory, antioxidant [5], antiviral [6], antimicrobial [7], and antifungal activities [8]. An array of phytochemical constituents, namely, $\alpha$-amyrin, uvaol [9], beta-diketones [10], kaempferol-3-glucoside, naringenin-glycoside [11], gnaphaliin, pinocembrin, tiliroside [12], eudesm-5-en11-ol [13], iso-italicene epoxide, $\beta$-costol, (Z)- $\alpha$-trans-bergamotol [14], and phloroglucinol $\alpha$-pyrone arzanol [15], were reported in $\mathrm{H}$. italicum.

Appendino et al. [15] started systematic study of phloroglucinol $\alpha$-pyrone class of compounds which possessed 


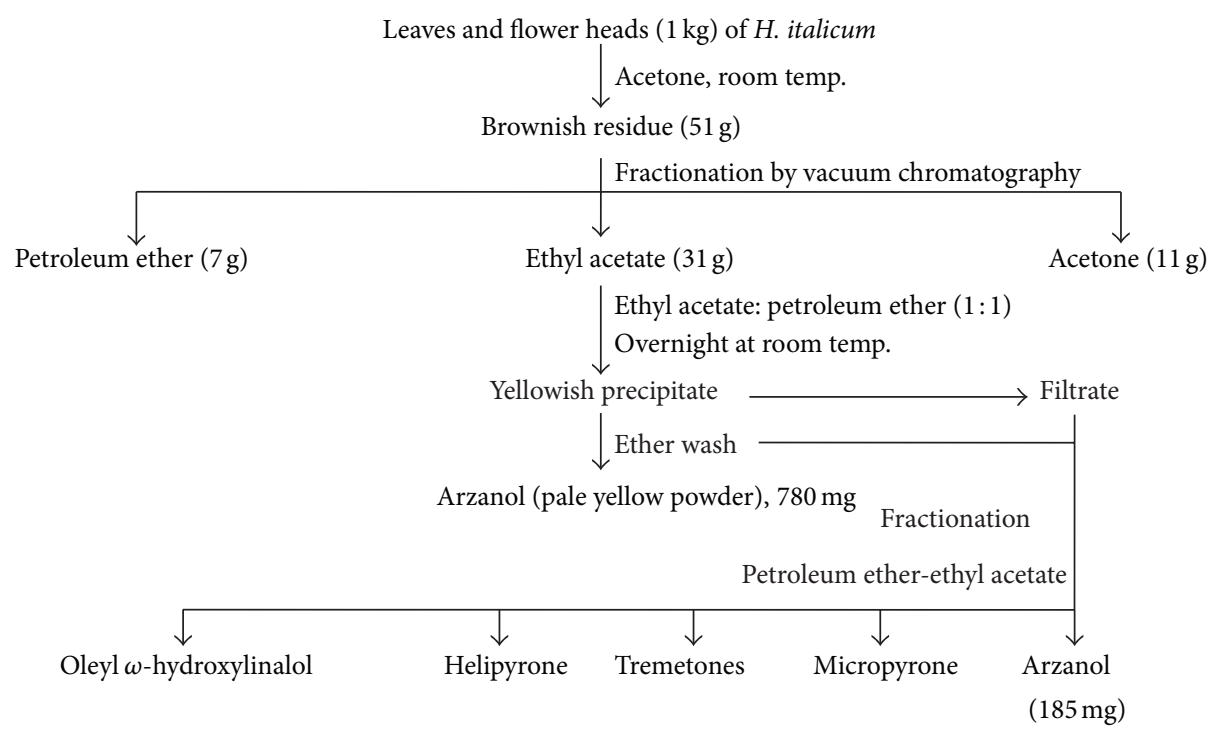

FIGURE 1: Schematic representation of isolation of phytochemical constituents of H. italicum subsp. microphyllum. (Adapted and modified from Appendino et al. [15].)

anti-inflammatory activity. They developed isolation techniques with high yield of compounds and screened them for anti-inflammatory activity. Arzanol, a prenylated heterodimeric phloroglucinyl pyrone, was firstly identified in early 2007 and detected as a major anti-inflammatory compound. It inhibits $\mathrm{NF} \kappa \mathrm{B}$ (nuclear factor kappa B) activation, release of proinflammatory mediators like interleukins (IL), TNF- $\alpha$, prostaglandin $\mathrm{E}_{2}\left(\mathrm{PGE}_{2}\right)$ [15], and inducible microsomal PGE ${ }_{2}$ synthase-1 (mPGES-1) [16]. Arzanol also inhibits HIV-1 replication in T cells; hence it has anti-HIV property [15]. Antioxidant and cytotoxic action of arzanol were studied by [17]. Hence, present review will focus on the isolation, chemistry, and pharmacology of the arzanol.

\section{Isolation and Identification of Arzanol}

The H. italicum, a best known medicinal plant from the Mediterranean area, was used as an anti-inflammatory and anti-infective plant in Greek-Roman system of medicine. Appendino et al. [15] developed an extraction and isolation procedure of arzanol from the acetone extract of aerial parts, mainly leaves and flower heads of $H$. italicum. The acetone extract showed potent NF- $\kappa \mathrm{B}$-inhibitory activity; in an attempt to identify the active compounds, the acetone extract was separated by solid-phase extraction into three fractions (petroleum ether-ethyl acetate, and acetone). They succeeded in isolating a pale yellow compound with powerful NF- $\kappa \mathrm{B}$ inhibiting activity $\left(\mathrm{IC}_{50}=5 \mu \mathrm{g} / \mathrm{mL}\right)$, superior to that of all the other products obtained by bioassay-directed fractionation of the mother liquors by gravity column chromatography. Approximately $780 \mathrm{mg}$ of arzanol was isolated from the extracts representing $1 \mathrm{~kg}$ dried aerial parts, mainly leaves and flower heads of $H$. italicum, as shown in Figure 1 and was identified and characterized by spectroscopic methods [15-18].

\section{Chemistry of Arzanol}

Arzanol belongs to phloroglucinol $\alpha$-pyrone category. Structure of arzanol is identical with homoarenol, (Figure 2(a)) which was isolated from $H$. arenarium $\mathrm{L}$. Moench species [19]. Appendino et al. [15] derived the name "arzanol" on the basis of plant $H$. italicum collected from Sardinian villageArzana.

Arzanol is a prenylated heterodimeric phloroglucinyl $\alpha$-pyrone chemically known as 3-(3-acetyl-2,4,6-trihydroxy5-(3-methylbut-2-en-1-yl)benzyl)-6-ethyl-4-hydroxy-5methyl-2H-pyran-2-one (Figure 2(b)).

\subsection{Synthesis of Arzanol (Figure 3) [20, 21]}

3.1.1. Step I: Formation of Prenylated Acylphloroglucinol. Phloroacetophenone (i) reacted with tert-butyldimethylsilyl chloride (TBDMSCl) for the protection of nonchelated hydroxyls of phloroacetophenone. In presence of prenyl alcohol, tetraphenylporphyrin (TPP) and toluene phloroacetophenone are converted into prenylated acylphloroglucinol (ii).

3.1.2. Step II: Formation of Reactive Methylene-2,4 Dioxypyrone. Acylation of the dianion of ethyl 3-oxopentanoate (iv) with ethyl acetoacetate followed by cyclodehydration lead to formation of $\alpha$-pyrone (vi). Compound (vi) which reacted with paraformaldehyde gives reactive methylene-2,4 dioxypyrone.

3.1.3. Step III: Desilylation of Prenylated Acylphloroglucinol and Formation of Arzanol. Indirect deprotonation of the phloroacetophenone (iii) by fluoride-induced desilylation using TBAF (tetrabutylammonium fluoride) and mixture of compound (vi) and paraformaldehyde in a warm $40^{\circ} \mathrm{C}$ chloroform affords arzanol (vii) with yield of $60 \%$. 
<smiles>CCc1oc(=O)c(Cc2c(O)c(CC=C(C)C)c(O)c(C(C)=O)c2O)c(O)c1C</smiles>

(A)<smiles>CCc1oc(=O)c(Cc2c(O)c(O)c(C(C)=O)c(CC=C(C)C)c2O)c(C)c1O</smiles>

(B)

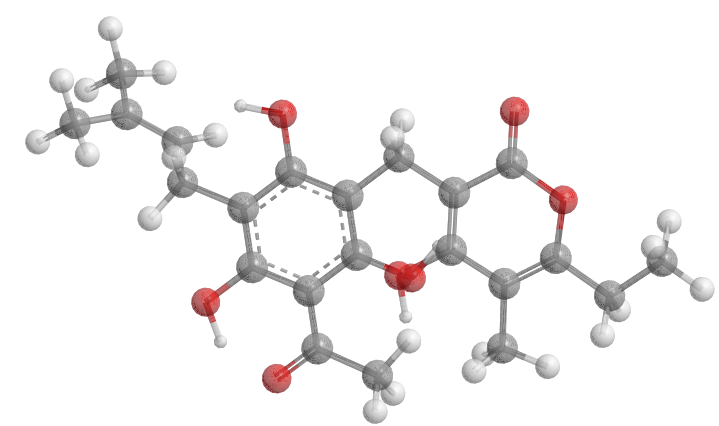

(b)

Figure 2: (a) Chemical structure of arzanol (A) and homoaranol (B), (b) 3D structure of arzanol: 3-(3-acetyl-2,4,6-trihydroxy-5-(3methylbut-2-en-1-yl)benzyl)-6-ethyl-4-hydroxy-5-methyl-2H-pyran-2-one.

3.2. Structure-Activity Relationship (SAR) of Arzanol. Minassi et al. [21] focussed on the alkylidene linker and pyrone moiety to find out structure activity relationship of arzanol (Figure 4). The pharmacological activity of derivatives of arzanol was assayed using inhibitory potency towards mPGES-1 and 5-LOX.

(a) In a compound ( vii $_{\mathrm{a}}$ ) replacement of $\mathrm{CH}_{3}$ to $\mathrm{H}$ at $\mathrm{R}_{2}$ and $\mathrm{R}_{3}$ position from pyrone ring does not affect the biological activity.

(b) Addition of methyl group at $\mathrm{R}_{1}$ on alkylidene linker ( $\mathrm{vii}_{\mathrm{b}}$ and $\mathrm{vii}_{\mathrm{c}}$ ) slightly decreased the activity against mPGES-1 and 5-LOX.

(c) n-Hexyl residue attached to $\mathrm{R}_{1}$ ( vii $_{\mathrm{d}}$ and vii $_{\mathrm{e}}$ ) to analyse the effect of elongated alkyl group leads to beneficial effect. Those compounds have higher mPGES-1 and 5-LOX inhibitory potency over vii ${ }_{\mathrm{a}}$.

(d) The benzylidene derivatives ( $\operatorname{vii}_{\mathrm{f}}$ and $\mathrm{vii}_{\mathrm{g}}$ ) showed an increased potency towards mPGES-1; hence lipophilic compound at alkylidene linker is beneficial for bioactivity.

(e) O-alkylation of pyrone moiety (viii) have only 5LOX inhibitory activity and inactive for inhibition of mPGES-1 activity. It suggests that presence of acidic group is responsible for mPGES-1 activity of arzanol.

\section{Pharmacological Role of Arzanol in Treatment of Inflammation}

Acetophenone, $\gamma$-pyrone, and flavonoids have been isolated from the aerial parts of $H$. italicum. 4-Hydroxy3-(3-methyl-2-butenyl) acetophenone reported inhibitory effect on cyclooxygenase and 5-lipoxygenase, while $\gamma$ pyrone glycoside acts as inhibitor of phospholipase $A_{2}$. Flavonoids, namely, gnaphaliin, pinocembrin, and tiliroside, were screened for antioxidant and anti-inflammatory activity. Tilirosides were found to be potent anti-inflammatory flavonoids with respect to Phospholipase $\mathrm{A}_{2}$ inhibition [5, $12,22]$. Phloroglucinol $\alpha$-pyrone (Arzanol), an isolated compound from acetone extract of $H$. italicum and have potent mPGES-1 inhibitor activity [16].

Eicosanoid biosynthesis involves various enzymes such as phospholipase, cyclooxygenase (COX), lipoxygenase (LOX), and microsomal $\mathrm{PGE}_{2}$ synthase (mPGES-1/mPGES-2) enzymes (Figure 5). Phospholipase $\mathrm{A}_{2}$ activated by some chemical and mechanical stimuli results in release of arachidonic acid from membrane phospholipids. COX-1/ COX-2 is responsible for conversion of arachidonic acid to $\mathrm{PGG}_{2}$ and further into $\mathrm{PGH}_{2}$. Prostanoids like $\mathrm{PGD}_{2}, \mathrm{PGE}_{2}$, $\mathrm{PGF}_{2 \alpha}, \mathrm{PGI}_{2}$, and $\mathrm{TXA}_{2}$ are synthesised from $\mathrm{PGH}_{2}$ in cellspecific manner by PGDS, mPGES-1/mPGES-2, PGFS, PGIS, and TXS enzymes, respectively. LOX is involved in synthesis of leukotrienes $\left(\mathrm{LTA}_{4}, \mathrm{LTB}_{4}, \mathrm{LTC}_{4}, \mathrm{LTD}_{4}\right.$, and $\left.\mathrm{LTE}_{4}\right)$ [23-25]. Prostanoids, that is, $\mathrm{PGI}_{2}, \mathrm{PGE}_{2}$, and $\mathrm{TXA}_{2}$, are derived from COX enzyme. $\mathrm{PGI}_{2}$ derived from COX-2 plays a role in induction of vasodilatation, inhibition of platelet 


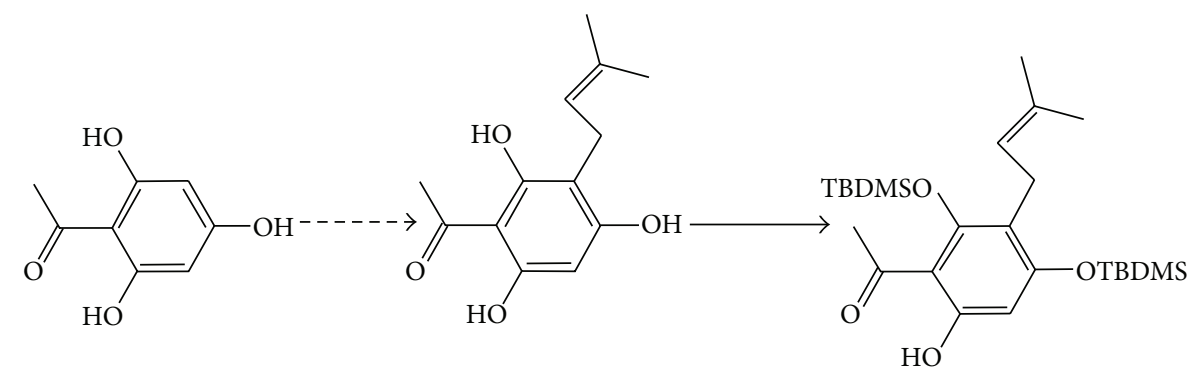

(i)

(ii)

(iii)



(iv)

(v)

(vi)

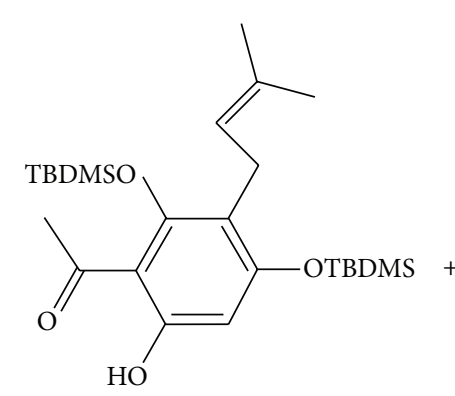

(iii)<smiles>CCc1oc(=O)cc(O)c1C</smiles>

(vi)

(vii)

Figure 3: Synthesis of arzanol. (Adapted from Minassi et al. [20, 21].)

aggregation, vascular smooth muscle cell proliferation inhibition, and decreased cholesterol accumulation [26]. COX-1 derived $\mathrm{TXA}_{2}$ is responsible for vasoconstriction and platelet aggregation; this effect of $\mathrm{TXA}_{2}$ does not alter by the use of COX-2 inhibitors. Hence, imbalance between $\mathrm{PGI}_{2}$ and $\mathrm{PGE}_{2}$ is responsible for cardiovascular side effects of COX-2 inhibitors $[23,27]$.

Prostaglandin $\mathrm{E}_{2}\left(\mathrm{PGE}_{2}\right)$ is a bioactive lipid synthesized by sequential action of cyclooxygenase, which specifically converts arachidonic acid into prostaglandin $\mathrm{H}_{2}\left(\mathrm{PGH}_{2}\right)$. A downstream signaling cascade by specific terminal membrane associated PGES-1 (mPGES-1), PGES-2 (mPGES-2) and cytosolic PGES (cPGES) have been identified and demonstrated to possess specific enzymatic activity mediating the conversion of $\mathrm{PGH}_{2}$ into $\mathrm{PGE}_{2}$ (Figure 5). mPGES-1 is a membrane bound, glutathione dependant enzymes involved in eicosanoids metabolism, induced by proinflammatory cytokines. It was proposed that mPGES-1 is functionally coupled to COX-2 and mediates the late phase of
$\mathrm{PGE}_{2}$ production $[28,29]$. Overexpression of COX-2, IL- $1 \beta$, and tumor necrosis factor (TNF)- $\alpha$ causes rises in level of mPGES-1 which leads to production of $\mathrm{PGE}_{2}$ in inflammation $[3,29,30] . \mathrm{PGE}_{2}$ plays critical roles in wide range of biological processes, including inflammation, cancer, blood pressure regulation, pain sensation, febrile response, and reproduction [31]. The physiological roles of $\mathrm{PGE}_{2}$ are mediated in part through activation of key downstream signaling cascades via transmembrane EP receptors located on the cell surface. $\mathrm{PGE}_{2}$ receptors $\mathrm{EP} 1, \mathrm{EP} 2, \mathrm{EP} 3$, and $\mathrm{EP} 4$ are present in spinal neurons [pain response], ovarian cells [maturation of ovulation], organum vasculosum lamina terminalis (OVLT) at the midline of the preoptic area (POA) [Fever generation], and osteoclast [Bone resorption], respectively [32]. Receptor specific binding can activate diverse pathways that regulate cell proliferation, apoptosis, angiogenesis, inflammation, and immune surveillance. Hence,targeting to mPGES leads to decrease in $\mathrm{PGE}_{2}$ levels and help in reduction of cardiovascular side effects of the COX-2 inhibitors. 


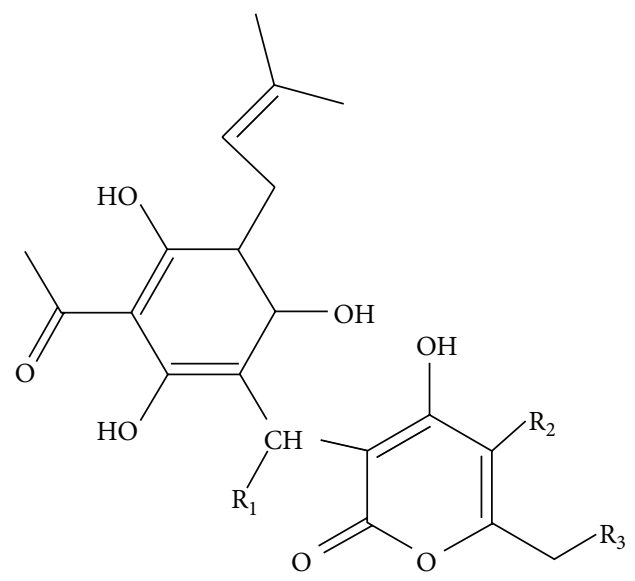

(vii)

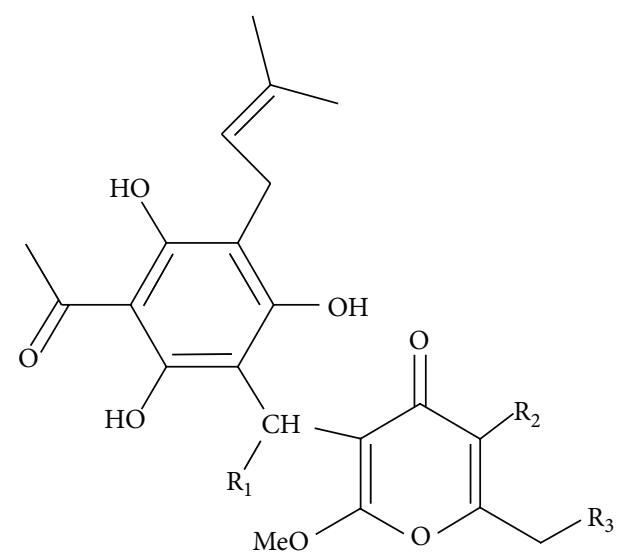

(viii)

$\begin{array}{cccc} & \mathrm{R}_{1} & \mathrm{R}_{2} & \mathrm{R}_{3} \\ \text { vii } & \mathrm{H} & \mathrm{Me} & \mathrm{Me} \\ \text { vii }_{\mathrm{a}} & \mathrm{H} & \mathrm{H} & \mathrm{H} \\ \text { vii }_{\mathrm{b}} & \mathrm{Me} & \mathrm{Me} & \mathrm{Me} \\ \text { vii }_{\mathrm{c}} & \mathrm{Me} & \mathrm{H} & \mathrm{H} \\ \text { vii }_{\mathrm{d}} & \mathrm{nC}_{6} \mathrm{H}_{13} & \mathrm{Me} & \mathrm{Me} \\ \text { vii }_{\mathrm{e}} & \mathrm{nC}_{6} \mathrm{H}_{13} & \mathrm{H} & \mathrm{H} \\ \text { vii }_{\mathrm{f}} & \mathrm{Ph} & \mathrm{Me} & \mathrm{Me} \\ \text { vii }_{\mathrm{g}} & \mathrm{Ph} & \mathrm{H} & \mathrm{H}\end{array}$

FIGURE 4: Structure-activity relationship of arzanol and its derivatives. (Adapted from Minassi et al. [21].)

Membrane phospholipids



FIGURE 5: Biosynthesis of eicosanoid. (Adapted and modified from Dallaporta et al. [23].) 




FIGURE 6: Site of action of arzanol and other anti-inflammatory agents.

Figure 6 reflects the site of action of arzanol; it inhibits the mPGES-1 enzyme which plays a important role in conversion of $\mathrm{PGH}_{2}$ to $\mathrm{PGE}_{2}$. Formation of $\mathrm{PGE}_{2}$ in intact human monocytes was determined to evaluate mechanistic activity of arzanol by Bauer et al. [16]. The results showed arzanol could inhibit $\mathrm{PGE}_{2}$ formation either interference with COX-2 expression or mPGES-1. The mPGES-1 inhibitory activity of arzanol was evaluated by preparing crude mPGES1 in microsomes of IL- $1 \beta$-stimulated A549 cells. Arzanol concentration-dependently inhibited $\mathrm{PGE}_{2}$ formation having superior over the mPGES-1 inhibitor MK-886 which was used as control. Despite, heat inactivation of microsomal preparations A549 cells for $15 \mathrm{~min}$ at $65^{\circ} \mathrm{C}$, the nonenzymatic $\mathrm{PGE}_{2}$ formation was not affected by arzanol. It clearly suggests that arzanol is a specific mPGES-1 inhibitor. Arzanol not only is mPGES-1 inhibitor but also proved as inhibitor of other proinflammatory mediators $\mathrm{TXB}_{2}$ and leukotrienes by inhibiting 5-LOX and COX-1 enzymes.

In vivo model of acute inflammation for evaluation of arzanol was carried out through carrageenan-induced pleurisy in rats. Arzanol (3.6 mg/kg, i.p.) treatment on carrageenan injected in plural cavity of rats significantly reduces exudate formation (59\%), cell infiltration (48\%), and inhibition of $\mathrm{PGE}_{2}$ (47\%). However, levels of $\mathrm{LTB}_{4}$ and 6-keto $\mathrm{PGF}_{1 \alpha}$ attenuate to only $31 \%$ and $27 \%$, respectively. In conclusion, decreased $\mathrm{PGE}_{2}$ level may contribute to the inhibition of mPGES-1 by arzanol. Hence, in vivo and in vitro studies reveal that arzanol is novel eicosanoid inhibitor that importantly acts on $\mathrm{PGE}_{2}$ synthesis [16].

Previously, arzanol proved as a potent $\mathrm{NF} \kappa \mathrm{B}$ inhibitor [15]. NF $\kappa \mathrm{B}$ is involved in activation of large number of genes in response to infections, inflammation, and other stressful situations requiring rapid reprogramming of gene expression [33]. Mechanism of action of arzanol on NFKB inhibition is explained in later part of this paper.

\section{Other Pharmacological Role}

5.1. Anti-HIV Activity. Overwhelming immune activation is the main feature of progression of HIV infection. This immune activation manifested by increased $B$ cell activation, T cell turnover, proinflammatory cytokines, and chemokines [34]. Immune activation leads to generation of activated $\mathrm{T}$ cell targets for the virus itself, further viral replication process, and host cell transcription and proliferation. Once new CD4+ T cells are locally activated and infected, they in turn infect other activated cells, amplifying the initial events [35]. Increasing evidence for cytotoxic T lymphocytes (CTL) in the host defence indicates a protective role against human immunodeficiency virus (HIV) whereas their decline is usually coincident with diseased progression [36].

$\mathrm{NF}-\kappa \mathrm{B}$ is one of the key regulators of genes involved in the immune/apoptotic response and is implicated in the regulation of several factors viz. cytokines, chemokines, adhesion molecules etc. Arzanol acts as an anti-HIV-1 agent, by inhibiting $\mathrm{NF} \kappa \mathrm{B}$ activation pathway (Figure 7$)[15,37,38]$. TNF- $\alpha$ induced $\mathrm{NF} \kappa \mathrm{B}$ activation pathway mediates HIV-1LTR transactivation in a $\mathrm{T}$ cell line. This activated pathway inhibited by arzanol was measured using luciferase enzyme level. Results showed that arzanol inhibited luciferase activity in concentration-dependent manner. The overall effect of arzanol shows it has anti-HIV activity by inhibiting HIV1 replication in $\mathrm{T}$ cells. Plant derived phloroglucinols and synthetically derived dimeric phloroglucinols are also being proved for their anti-HIV activity [39].

5.2. Antioxidant Activity. Oxidation is a process of transfer of electron molecule to an oxidizing substance. Oxidative stress develops due to generation of reactive oxygen species, namely, hydroxyl radicals $\left(\mathrm{OH}^{*}\right)$ and superoxide anions $\left(\mathrm{O}_{2}{ }^{-}, \mathrm{OOH}^{\bullet}\right)$ [40]. These radicals are scavenged by 


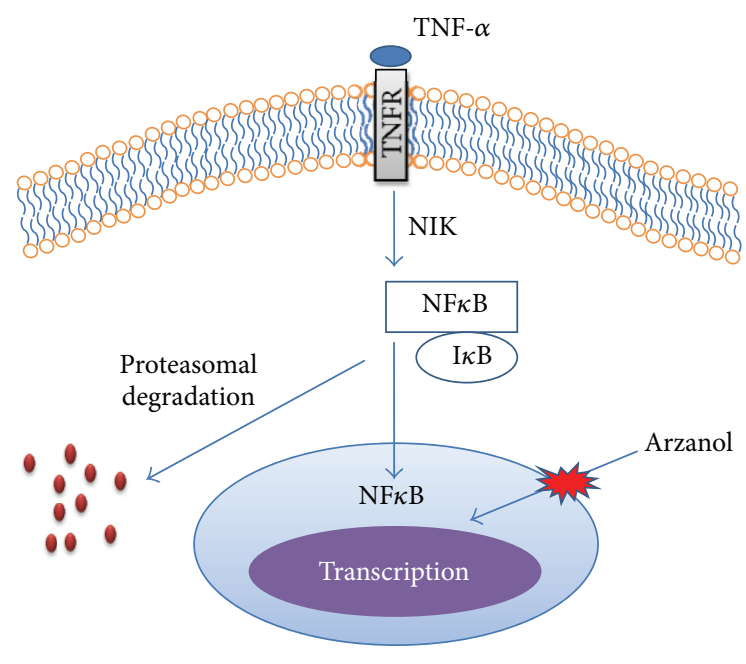

Figure 7: TNF- $\alpha$ mediated NF $\kappa$ B signal transduction pathway. TNF- $\alpha$ bind to TNFR (TNF- $\alpha$ receptor) lead to activation of NF$\kappa \mathrm{B}$ inducing kinase (NIK) which phosphorylates and activates $\mathrm{NF} \kappa \mathrm{B}$ and $\mathrm{I} \kappa \mathrm{B}$ (inhibitors of $\mathrm{NF} \kappa \mathrm{B}$ ) complex. IKK then phosphorylates $\mathrm{I} \kappa \mathrm{B}$, which leads to its ubiquitination and degradation by the proteasome. NF- $\kappa \mathrm{B}$ then enters the nucleus and acts on target genes. Arzanol inhibit this $\mathrm{NF} \kappa \mathrm{B}$ activation involved in signal transduction pathway. (Adapted and modified from Appendino et al. [15].)

antioxidants which play an important role in the treatment of diabetes mellitus, inflammatory diseases, atherosclerosis, and carcinogenesis [41].

Rosa et al. [17] investigated antioxidant activity on linoleic acid assay, cholesterol assay, and cell culture method. Linoleic acid autoxidation mediated by $\mathrm{FeCl}_{3}$, EDTA causes generation of linoleic acid peroxyl radicals (LOO'). Results show arzanol inhibits this oxidation process completely at $5 \mathrm{nmol}$ while $90 \%$ and $45 \%$ protection occur at 2.5 and $1 \mathrm{nmol}$ concentration, respectively. Cholesterol degradation and formation 7-keto and $7 \beta-\mathrm{OH}$ derivatives were significantly inhibited by arzanol $(10 \mathrm{nmol})$ at 1 and $2 \mathrm{~h}$. Oxidative stress in VERO cell line was induced by TBH (tertbutyl hydroperoxide) and arzanol showed significant $40 \%$ reduction in production of malondialdehyde (MDA). These investigators also proved arzanol is noncytotoxic up to $40 \mu \mathrm{M}$ in vitro tested in VERO cell culture models [17].

\section{Conclusion and Future Perspectives}

Arzanol, prenylated heterodimeric phloroglucinyl pyrone, isolated from $H$. italicum subsp. microphyllum. have major anti-inflammatory, antiviral (anti-HIV), and antioxidant activities. Arzanol inhibits NF $\mathrm{B}$ B activation, HIV replication in $\mathrm{T}$ cells, releases of proinflammatory mediators like IL$1 \beta$, IL-6, IL- 8 , and TNF- $\alpha$, and biosynthesis of PGE Py $_{2}$ potentially inhibiting mPGES-1 enzyme. Arzanol was widely studied for its pharmacodynamic profile while pharmacokinetic profile still needs to be established. In future, diversity of mechanism of actions of arzanol may be useful in treatment of cancer.
Although, an extensive amount of research work has been done on anti-inflammatory compounds to date, mPGES inhibitors like arzanol are still unknown. Only a few species from genus Helichrysum have been investigated [42]. Consequently, a broad field of future research remains possible in which the isolation of new active principles (mPGES-1 inhibitors) from the genus Helichrysum would be of great scientific merit.

\begin{tabular}{|c|c|}
\hline \multicolumn{2}{|c|}{ Abbreviations } \\
\hline COX: & Cyclooxygenase \\
\hline CTL: & Cytotoxic T lymphocytes \\
\hline HIV: & Human immunodeficiency virus \\
\hline IKK: & I $\kappa$ B kinase \\
\hline IL: & Interleukins \\
\hline LOX: & Lipoxygenase \\
\hline MDA: & Malondialdehyde \\
\hline mPGES: & Microsomal $\mathrm{PGE}_{2}$ synthase \\
\hline $\mathrm{NF} \kappa \mathrm{B}:$ & Nuclear factor kappa B \\
\hline NIK: & $\mathrm{NF}-\kappa \mathrm{B}$ inducing kinase \\
\hline OVLT: & Organum vasculosum lamina terminalis \\
\hline PAF: & Platelet-activating factor \\
\hline $\mathrm{PGD}_{2}$ : & Prostaglandin $\mathrm{D}_{2}$ \\
\hline PGDS: & Prostaglandin D synthase \\
\hline $\mathrm{PGE}_{2}:$ & Prostaglandin $\mathrm{E}_{2}$ \\
\hline PGES: & Prostaglandin E synthase \\
\hline $\mathrm{PGF}_{2 \alpha}:$ & Prostaglandin $\mathrm{F}_{2 \alpha}$ \\
\hline PGFS: & Prostaglandin F synthase \\
\hline $\mathrm{PGG}_{2}$ : & Prostaglandin $\mathrm{G}_{2}$ \\
\hline $\mathrm{PGH}_{2}$ : & Prostaglandin $\mathrm{E}_{2}$ \\
\hline $\mathrm{PGI}_{2}$ : & Prostaglandin $\mathrm{I}_{2}$ \\
\hline PGIS: & Prostaglandin I synthase \\
\hline $\mathrm{PLA}_{2}:$ & Phospholipase $\mathrm{A}_{2}$ \\
\hline POA: & Preoptic area \\
\hline TBAF: & Tetrabutylammonium fluoride \\
\hline TBDMSCl: & tert-Butyldimethylsilyl chloride \\
\hline TBH: & tert-Butyl hydroperoxide \\
\hline TNF- $\alpha$ : & Tumour necrosis factor- $\alpha$ \\
\hline TPA: & Tissue plasminogen activator \\
\hline TPP: & Tetraphenylporphyrin \\
\hline $\mathrm{TXA}_{2}$ : & Thromboxane $\mathrm{A}_{2}$ \\
\hline TXS: & Thromboxane synthase. \\
\hline
\end{tabular}

\section{Conflict of Interests}

The authors declare that there is no conflict of interests regarding the publication of this paper.

\section{References}

[1] N. Chand and P. Eyre, "Nonsteroidal anti inflammatory drugs: a review. New applications in hypersensitivity reactions of cattle and horses," Canadian Journal of Comparative Medicine, vol. 41, no. 3, pp. 233-240, 1977.

[2] B. Halliwell, J. R. Hoult, and D. R. Blake, "Oxidants, inflammation, and anti-inflammatory drugs," FASEB Journal, vol. 2, no. 13, pp. 2867-2873, 1988. 
[3] M. Nakanishi, V. Gokhale, E. J. Meuillet, and D. W. Rosenberg, "MPGES-1 as a target for cancer suppression. A comprehensive invited review 'phospholipase A2 and lipid mediators," Biochimie, vol. 92, no. 6, pp. 660-664, 2010.

[4] J. Mastelič, O. Politeo, and I. Jerkovič, "Contribution to the analysis of the essential oil of Helichrysum italicum (Roth) G. Dondetermination of ester bonded acids and phenols," Molecules, vol. 13, no. 4, pp. 795-803, 2008.

[5] A. Sala, M. del Carmen Recio, R. M. Giner et al., "Anti-inflammatory and antioxidant properties of Helichrysum italicum," Journal of Pharmacy and Pharmacology, vol. 54, no. 3, pp. 365-371, 2002.

[6] A. Nostro, M. A. Cannatelli, A. Marino et al., "Evaluation of antiherpesvirus-1 and genotoxic activities of Helichrysum italicum extract," New Microbiologica, vol. 26, no. 1, pp. 125-128, 2003.

[7] J. Mastelic, O. Politeo, I. Jerkovic, and N. Radosevic, "Composition and antimicrobial activity of Helichrysum italicum essential oil and its terpene and terpenoid fractions," Chemistry of Natural Compounds, vol. 41, no. 1, pp. 35-40, 2005.

[8] A. Angioni, A. Barra, M. Arlorio et al., "Chemical composition, plant genetic differences, and antifungal activity of the essential oil of Helichrysum italicum G. Don ssp. microphyllum (Willd) Nym," Journal of Agricultural and Food Chemistry, vol. 51, no. 4, pp. 1030-1034, 2003.

[9] G. Orzalesi, T. Mezzetti, and V. Bellavita, "A new natural triterpenic lactone, alpha-amyrin and uvaol from Helichrysum italicum (G. Don)," Bollettino Chimico Farmaceutico, vol. 108, no. 9, pp. 540-545, 1969.

[10] C. G. Casinovi, C. Galeffi, A. Pela, S. Tira, and G. Di Modica, "New beta-diketones from Helichrysum italicum G. Don," Annali dell'Istituto Superiore di Sanita, vol. 4, no. 3, pp. 186-198, 1968.

[11] R. M. Facino, M. Carini, L. Franzoi, O. Pirola, and E. Bosisio, "Phytochemical characterization and radical scavenger activity of flavonoids from Helichrysum italicum G. Don (compositae)," Pharmacological Research, vol. 22, no. 6, pp. 709-721, 1990.

[12] A. Sala, M. C. Recio, G. R. Schinella et al., "Assessment of the anti-inflammatory activity and free radical scavenger activity of tiliroside," European Journal of Pharmacology, vol. 461, no. 1, pp. 53-61, 2003.

[13] A. Bianchini, F. Tomi, P. Richomme, A. Bernardini, and J. Casanova, "Eudesm-5-en-11-ol from Helichrysum italicum essential oil," Magnetic Resonance in Chemistry, vol. 42, no. 11, pp. 983984, 2004.

[14] E. Mancini, L. de Martino, A. Marandino, M. R. Scognamiglio, and V. de Feo, "Chemical composition and possible in vitro phytotoxic activity of Helichrysum italicum (Roth) don ssp. italicum," Molecules, vol. 16, no. 9, pp. 7725-7735, 2011.

[15] G. Appendino, M. Ottino, N. Marquez et al., "Arzanol, an antiinflammatory and anti-HIV-1 phloroglucinol $\alpha$-pyrone from Helichrysum italicum ssp. microphyllum," Journal of Natural Products, vol. 70, no. 4, pp. 608-612, 2007.

[16] J. Bauer, A. Koeberle, F. Dehm et al., "Arzanol, a prenylated heterodimeric phloroglucinyl pyrone, inhibits eicosanoid biosynthesis and exhibits anti-inflammatory efficacy in vivo," Biochemical Pharmacology, vol. 81, no. 2, pp. 259-268, 2011.

[17] A. Rosa, M. Deiana, A. Atzeri et al., "Evaluation of the antioxidant and cytotoxic activity of arzanol, a prenylated $\alpha$-pyronephloroglucinol etherodimer from Helichrysum italicum subsp. microphyllum," Chemico-Biological Interactions, vol. 165, no. 2, pp. 117-126, 2007.
[18] A. Rosa, F. Pollastro, A. Atzeri et al., "Protective role of arzanol against lipid peroxidation in biological systems," Chemistry and Physics of Lipids, vol. 164, no. 1, pp. 24-32, 2011.

[19] J. Vrkoč, L. Dolejš, P. Sedmera, S. Vašíčková, and F. Šorm, “The structure of arenol and homoarenol, $\alpha$-pyrone derivatives from Helichrysum arenaricum (L.) moench," Tetrahedron Letters, vol. 12, no. 3, pp. 247-250, 1971.

[20] A. Minassi, A. Giana, A. Ech-Chahad, and G. Appendino, "A regiodivergent synthesis of ring A C-prenylflavones," Organic Letters, vol. 10, no. 11, pp. 2267-2270, 2008.

[21] A. Minassi, L. Cicione, A. Koeberle et al., "A multicomponent carba-Betti strategy to alkylidene heterodimers-total synthesis and structure-activity relationships of arzanol," European Journal of Organic Chemistry, no. 4, pp. 772-779, 2012.

[22] A. Sala, M. del Carmen Recio, R. M. Giner, S. Máñez, and J. Ríos, "New acetophenone glucosides isolated from extracts of Helichrysum italicum with antiinflammatory activity," Journal of Natural Products, vol. 64, no. 10, pp. 1360-1362, 2001.

[23] M. Dallaporta, E. Pecchi, S. Thirion, A. Jean, and J. Troadec, "Towards the management of inflammation: recent developments of mPGES-1 inhibitors," Recent Patents on CNS Drug Discovery, vol. 5, no. 1, pp. 70-80, 2010.

[24] W. L. Smith, "The eicosanoids and their biochemical mechanisms of action," Biochemical Journal, vol. 259, no. 2, pp. 315324, 1989.

[25] A. Schneider, Y. Zhang, M. Zhang et al., "Membrane-associated PGE synthase-1 (mPGES-1) is coexpressed with both COX-1 and COX-2 in the kidney," Kidney International, vol. 65, no. 4, pp. 1205-1213, 2004.

[26] D. P. Hajjar and K. B. Pomerantz, "Signal transduction in atherosclerosis: integration of cytokines and the eicosanoid network," FASEB Journal, vol. 6, no. 11, pp. 2933-2941, 1992.

[27] J. B. Smith, H. Araki, and A. M. Lefer, "Thromboxane A2, prostacyclin and aspirin: effects on vascular tone and platetet aggregation," Circulation, vol. 62, no. 6, pp. V-19-V-25, 1980.

[28] J. Clàiria, "Cyclooxygenase-2 biology," Current Pharmaceutical Design, vol. 9, no. 27, pp. 2177-2190, 2003.

[29] D. O. Stichtenoth, S. Thorén, H. Bian, M. Peters-Golden, P. Jakobsson, and L. J. Crofford, "Microsomal prostaglandin E synthase is regulated by proinflammatory cytokines and glucocorticoids in primary rheumatoid synovial cells," Journal of Immunology, vol. 167, no. 1, pp. 469-474, 2001.

[30] M. Murakami, H. Naraba, T. Tanioka et al., "Regulation of prostaglandin $\mathrm{E}_{2}$ biosynthesis by inducible membrane-associated prostaglandin $\mathrm{E}_{2}$ synthase that acts in concert with cyclooxygenase-2," The Journal of Biological Chemistry, vol. 275, no. 42, pp. 32783-32792, 2000.

[31] T. Kobayashi and S. Narumiya, "Function of prostanoid receptors: studies on knockout mice," Prostaglandins and Other Lipid Mediators, vol. 68-69, pp. 557-573, 2002.

[32] C. D. Funk, "Prostaglandins and leukotrienes: advances in eicosanoid biology," Science, vol. 294, no. 5548, pp. 1871-1875, 2001.

[33] M. Karin and Y. Ben-Neriah, "Phosphorylation meets ubiquitination: the control of NF- $\kappa \mathrm{B}$ activity," Annual Review of Immunology, vol. 18, pp. 621-663, 2000.

[34] D. C. Douek, M. Roederer, and R. A. Koup, "Emerging concepts in the immunopathogenesis of AIDS," Annual Review of Medicine, vol. 60, pp. 471-484, 2009.

[35] Z. Grossman, M. B. Feinberg, and W. E. Paul, "Multiple modes of cellular activation and virus transmission in HIV infection: a role for chronically and latently infected cells in sustaining viral 
replication," Proceedings of the National Academy of Sciences of the United States of America, vol. 95, no. 11, pp. 6314-6319, 1998.

[36] A. M. Geretti, E. Hulskotte, and A. D. M. E. Osterhaus, "Cytotoxic T lymphocytes in AIDS pathogenesis: lessons to be learned from the macaque model of simian immunodeficiency virus infection," Journal of General Virology, vol. 79, no. 3, pp. 415421, 1998.

[37] V. Ayyavoo, A. Mahboubi, S. Mahalingam et al., "HIV-1 Vpr suppresses immune activation and apoptosis through regulation of nuclear factor $\kappa \mathrm{B}$," Nature Medicine, vol. 3, no. 10, pp. 1117-1123, 1997.

[38] T. D. Gilmore, "Introduction to NF- $\kappa$ B: players, pathways, perspectives," Oncogene, vol. 25, no. 51, pp. 6680-6684, 2006.

[39] S. K. Chauthe, S. B. Bharate, S. Sabde, D. Mitra, K. K. Bhutani, and I. P. Singh, "Biomimetic synthesis and anti-HIV activity of dimeric phloroglucinols," Bioorganic and Medicinal Chemistry, vol. 18, no. 5, pp. 2029-2036, 2010.

[40] J. M. Lin, C. C. Lin, M. F. Chen, T. Ujiie, and A. Takada, "Scavenging effects of Mallotus repandus on active oxygen species," Journal of Ethnopharmacology, vol. 46, no. 3, pp. 175-181, 1995.

[41] B. Halliwell, "Role of free radicals in the neurodegenerative diseases: therapeutic implications for antioxidant treatment," Drugs and Aging, vol. 18, no. 9, pp. 685-716, 2001.

[42] A. C. U. Lourens, A. M. Viljoen, and F. R. van Heerden, "South African Helichrysum species: a review of the traditional uses, biological activity and phytochemistry," Journal of Ethnopharmacology, vol. 119, no. 3, pp. 630-652, 2008. 

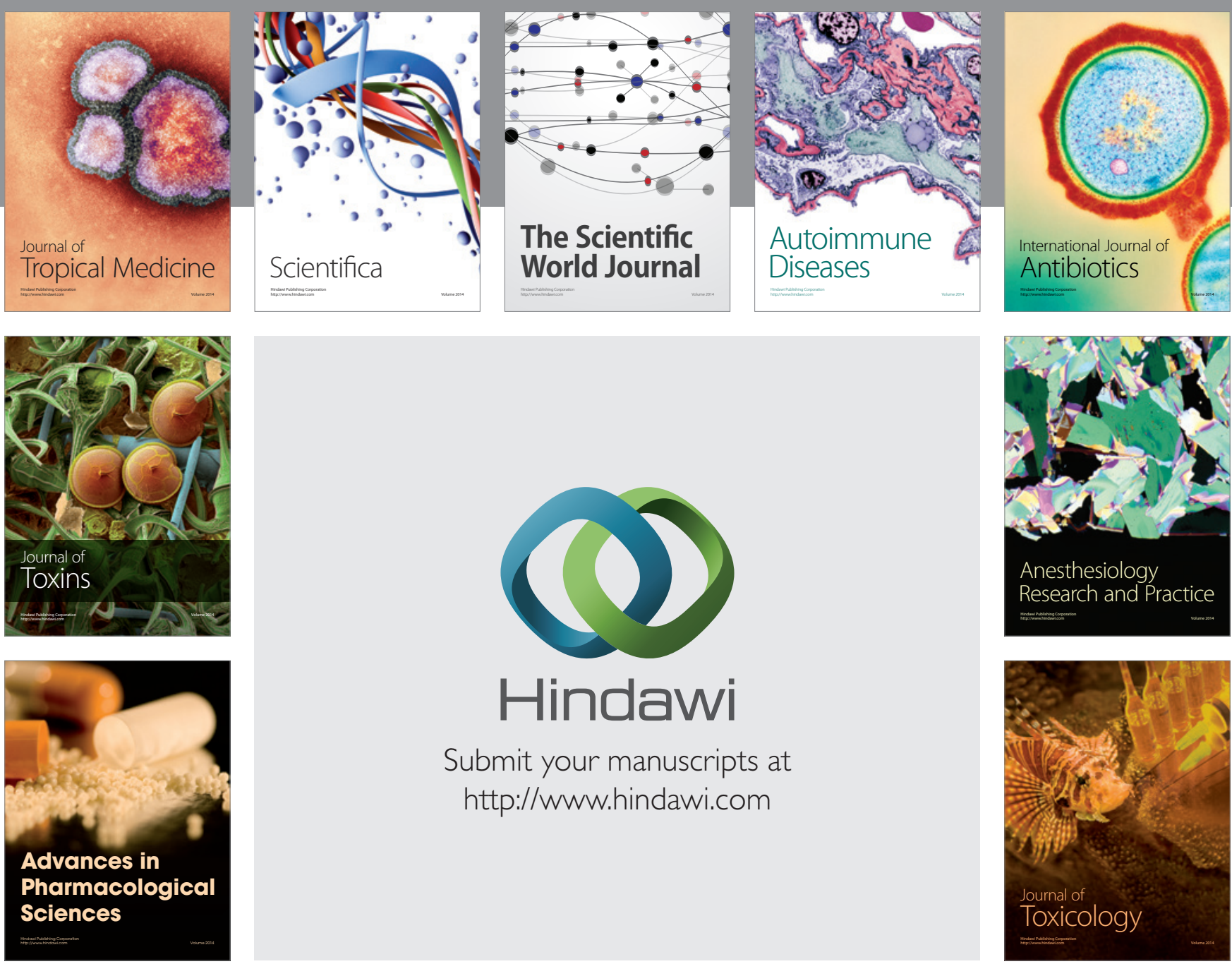

\section{Hindawi}

Submit your manuscripts at

http://www.hindawi.com
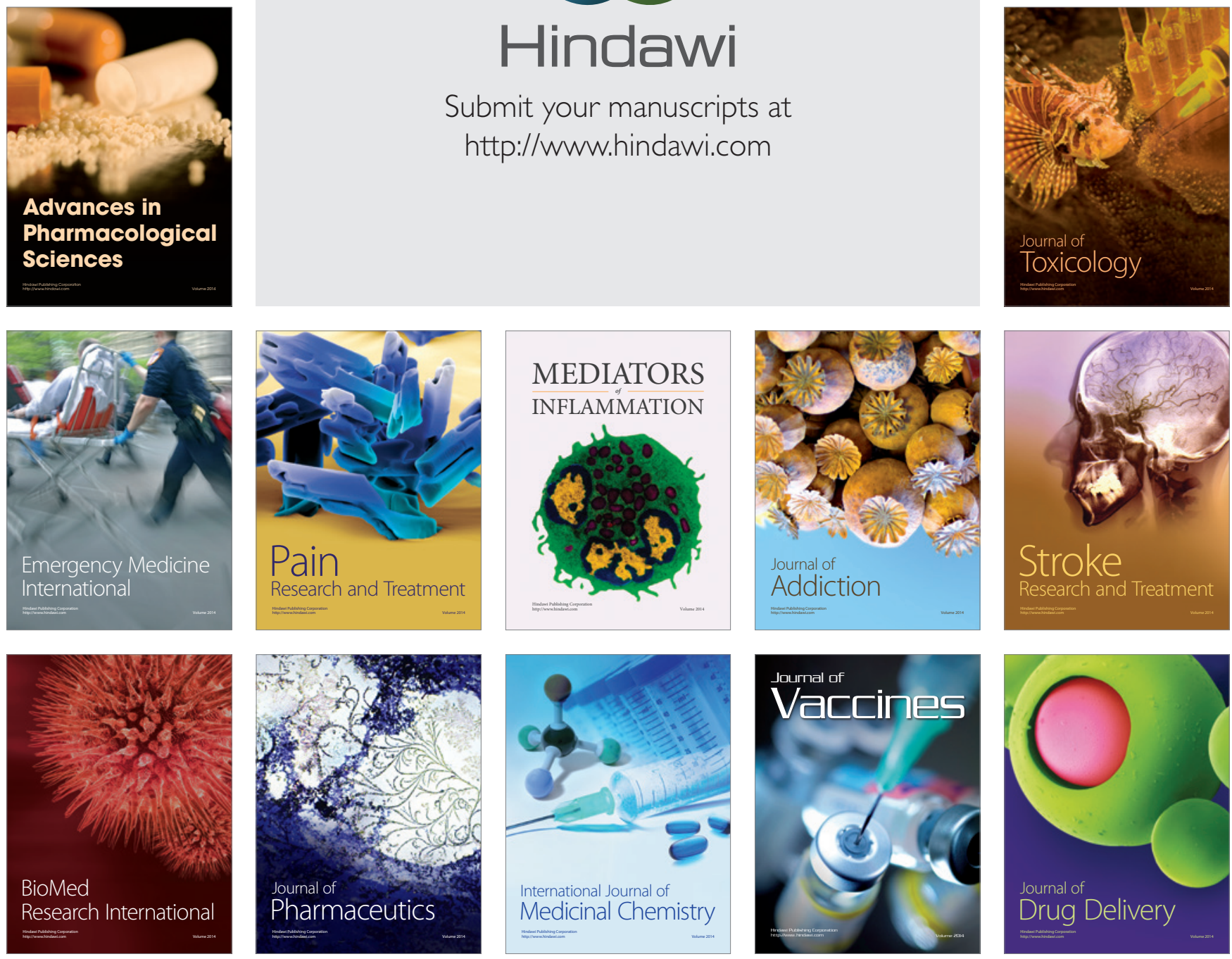